appropriate consideration of the recurrence of the great floods which geological evidence shows have occurred many times in the past. Such consideration would serve as a corrective against failure to realize adequately that a series of rains like that which produced the 1937 floods can recur, and also would tend to produce a more sound understanding and befitting humility as to the limitations of the works of man in effectiveness against all possible floods. Nature can produce floods which it may not be practicable for man to control, and it behoves man in the municipal and industrial development of river valleys not to overlook the need for meeting those events that are associated with flood catastrophes which it is not practicable for him to prevent.

\title{
Modern Study of Plants in Relation to Education*
}

\author{
By Prof. E. J. Salisbury, F.R.S.
}

$\mathrm{I}^{\mathrm{F}}$ we cast our minds back on the general attitude adopted towards botany in the latter part of the eighteenth century, we cannot but be struck by the almost apologetic phraseology of its votaries and the curious grounds upon which they rationalized its pursuit. Rousseau, for example, described botany as a study of pure curiosity that has no other real use than that which a thinking, sensible being may deduce from the observation of Nature and the wonders of the universe. I venture to think that many otherwise educated people to-day would express similar sentiments, though in more modern and probably less complimentary language.

The teaching of our subject has been in no small degree to blame for the widespread misconceptions as to its aims and content. For long regarded as a harmless and elegant occupation for the female sex, botany only survived as a study of practical utility because of the continued necessity for medical practitioners to acquire some knowledge of materia medica. How perfunctory was much of this teaching is indicated in that charming book, "Leaves from the Life of a Country Doctor", where the late C. B. Gunn describes how as a medical student in 1878 "the botany class gave me a 'scunner' at the subject which has lasted ever since".

The old technological significance for medicine has long since gone, but a newer and vastly more important significance remains, both cultural and vocational, which has rarely been stated, let alone stressed. Despite the vastly enlarged content of botanical knowledge since those days, the general conception of botany has remained much what it was then. The high value of botany as an educational subject and indeed its absolute necessity in any system of real cultural development are aspects which botanists have failed to present and emphasize.

* From the presidential address to Section K (Botany) of the British Association, delivered at Nottingham on September 2.
The protagonists of compulsory Greek and Latin of the last century valued very highly, and rightly so, the cultural content which a study of the humanities could provide. It is easy for us to be wise after the event, but now that the dust of that controversy has cleared away we can see that failure to apprehend that there are other approaches to the same mental salvation led to an unfortunate insistence upon the means rather than upon the end.

But whilst scientific workers justly claim that cultural value is the monopoly of no one subject and that those brought up in the classical tradition may be as much philistines as any man of science, it is undoubtedly true that the immense cultural potentialities of scientific thought have too often been neglected for the sake of mere erudition. There is a general tendency for university teaching to become more and more vocational as the specialized demands of occupations become increasingly exacting. Thus, not only do technological aspects grow more obtrusive, especially in the final courses of certain subjects, but also there is a trend, in the direction of this change, making its influence felt, further and further back in the student's training, so that we find, for example, certain sections of the medical profession demanding that the preliminary education should have a more direct bearing on the future occupation of the student, despite the fact that this can only be accomplished at the expense of their general education and culture. With the long course of training which most professions to-day require and the financial strain that this often involves upon parents, one cannot but sympathize in the wish to provide some relief, but if this is to be accomplished without detriment to the ultimate standing of the professions themselves, it can only be by an increased concentration on the more general aspects of culture in the schools. So far as biology 
is concerned, there is a widespread recognition for the need of greater attention to training in observation in the schools, allied to what may be termed the scientific study of natural history. Too much attention in this as in other subjects is paid to the acquisition of mere information, especially if recent, too little to the principles which are involved.

This is not intended as a stricture upon the teachers, since, with our present system, earlier and earlier in the students' career they are striving to achieve a dual objective-the training which should be their chief concern, and preparation for university examinations at a stage in mental development which cannot adequately appreciate the educational content of the curricula. Thus the student who has taken the intermediate examination from school is often handicapped in com. parison with those who would appear to be starting their university career in a less advanced stage.

Just as the increased demand for material things facilitated the replacement of the products of the craftsman by mass production of machine-made articles, so, too, the rapid increase of population following the Industrial Revolution inevitably led to something analogous to mass production in the education of children and the training of teachers.

Many there are who blame the examination system, which, however, with all its faults, if rightly used, is in reality a fairly efficient sieve for separation where large numbers are involved. But the examination machine is often expected to effect a grading of the human material with which it deals that can only be attained by more individual methods. As a consequence, undue importance is attached to examination results and a wrong emphasis is often laid on their significance. This leads to a premium being placed on mere erudition, and so subjects are liable to be taught not as living realities but, in the forceful phraseology used by Winston Churchill in one of his novels, "Knowledge is presented as a corpse which bit by bit we painfully dissect".

Furthermore, our educational methods are, I fear, too often divided in their allegiance ; on one hand we aim at the provision of a liberal culture which will make for the greatest happiness of the individual, considered in terms of mental contentment and an abiding resource in later life; whilst on the other hand we aim at the equipment of the student for the earning of his daily bread to ensure bodily comfort. We are not sufficiently trustful that the provision of the former is, to employ the expressive northern phraseology, the "gainest way" to the latter end, and so we adopt a sort of mental squint, which permits neither of the clear vision of the full beauty of integrated knowledge nor even of keeping our eyes on the main chance.
It is no more possible in education than in ethics to serve both God and Mammon. It is not merely good education but the apotheosis of worldly wisdom to seek first the cultural background and to believe that the vocational proficiency will be added unto you.

The universities cannot be held blameless for the lack of appreciation by the general public of the implications of our subject. May I, in this connexion, quote a passage from an American report on university education which loses none of its cogency on this side of the Atlantic: "Appointing authorities too often place undue stress on specialisation, instead of placing adequate emphasis on scholarly background, versatility of intellectual interest and general culture".

Whilst activity and distinction in research is a necessary qualification of the teacher, the capacity to impart knowledge to others is no less essential. Too often in the selection for university posts, aptitude as a teacher, which should be a first consideration, is entirely subordinated to distinction as an investigator. No one, it is true, can be an inspiring teacher who does not possess intellectual initiative and who is not engaged in a creative pursuit, but most of us have suffered at one time or another from the investigator "whose thoughts are too full for words". Furthermore, we must avoid the undue sacrifice of breadth for depth for other reasons.

The accumulation of data and the provision of information bear much the same relation to the advancement of knowledge as artificial fertilizers to crop production. Just as our fertilizers must be properly balanced, so, too, our information must be so correlated and concerted that ignorance in one department does not become the limiting factor in our utilization of extensive data in others. In these days of extreme and increasing specialization, such correlation of effort is becoming more and more important, and it is to the universities, old and young alike, that we must look for the maintenance of that contact and synthesis which is essential to real progress. In particular, I should like to urge that the time has come when the curriculum required of those proceeding to a university degree in science should be reconsidered. It is, in the present state of knowledge, as much an anachronism that a student should be able to proceed to a degree in chemistry having no knowledge of biology as that he should proceed to a degree in botany with a mere smattering of either physics or chemistry. Anyone who aspires to a degree in science should in my opinion have an adequate appreciation of the principles of physics, chemistry, mathematics, especially as regards statistical methods and probability theory, and lastly, but by. no means least, one biological 
subject. It may be stressed that some biological training is to-day an essential to any liberal culture and should be as much an obligatory part of a school curriculum as arithmetic.

One great merit of botanical study from the point of view of general education is that, if properly taught, it provides perhaps the best medium for training in accurate observation. Observation consists essentially of two separate processes, namely, seeing the object or phenomenon and the apprehension of what is seen. The visual perception of the good and bad observer may be alike adequate, but it is in the degree of their apprehension that they differ. To train such powers it is essential to check the accuracy of appreciation either by means of verbal description or graphic representation. The graphic method is clearly more suited to the adolescent mind, whose limited vocabulary and limited feeling and understanding of the nuances of meaning of words unduly restricts his verbal precision. Drawing, if regarded strictly as a statement of observed facts, offers the best means of such training, and botanical material, because of its well-defined organization, is peculiarly suited for this purpose.

[To be continued.]

\section{Surface Action in Biology}

A JOINT symposium including Sections A A (Mathematical and Physical Sciences), B (Chemistry) and I (Physiology) was held on this topic at the recent meeting at Nottingham of the British Association.

Since the development of the Langmuir trough in 1917, several new methods have been introduced into our armoury of weapons used for attacking the problems connected with film structure and film reactions. Of these, two have been developed in some detail and have provided us with numerous interesting and novel results, which appear to have far-reaching biological implications.

In the first method, a number of mono-layers of barium stearate are successively built up on a chromium-plated surface. Brilliant interference colours are observed when the film is viewed at a suitable angle in polarized light, conveniently obtained with the aid of a 'Polaroid' screen. The interference minima are so sharp that increments in thickness so small as 1.6 A. can be detected. If in the outer layer the divalent barium ions be replaced by ions of a higher valency, for example, thorium, the surface is now 'conditioned' in that it will adsorb monolayers of a variety of substances, for example, proteins or cholesterol. On these surfaces in turn adsorption of a second monolayer can take place, for example, digitonin on cholesterol but not on epicholesterol. It is found that many of these selective adsorptive reactions are highly specific.

By superimposing instead of a series of barium stearate monolayers, mixed films containing barium stearate and stearic acid are employed, the composite mixed membrane may be leached with stearic acid solvents, and a skeleton membrane of barium stearate remains. Such a skeleton can be refilled with various liquids, and the successful penetration followed by observing the changes in the refractive index of the layers. By sensitization of such a skeleton film and coating with a monolayer, it is evidently possible to examine the permeability of adsorbed monolayers to different solvents.

This optical method of examination provides us in the first place with an elegant means of determining whether adsorption has taken place or no, for example, in such reactions as the antibody antigen reaction. If in this case the surface reaction is indeed as specific as the bulk colloid reaction, it is evident that the method may well prove an agreeable substitute for the usual precipitation technique. In respect to sensitivity, we may note that one square centimetre (ample for optical examination) requires only $10^{-7} \mathrm{gm}$. for deposition. In the second place, the optical examination of skeleton membranes permits us to investigate both their permeability and ease of penetration by a variety of solvents. Since such penetration involves not only considerations of pore size but also of the extents of interaction between the penetrating molecular species and the material of the membrane, it is evidently a convenient method for obtaining information on each of these factors.

The second method of investigation involves determination of the force area characteristics, and the modification in the phase boundary potential caused by the presence of the film. Since in general terms the force area values give us information about the non-polar and the phase boundary potential provides us with knowledge about the polar portions of a complex organic molecule, it has been found possible to make fairly detailed analysis about the orientation of even complex film-forming systems. This applies especially to substances existing in what is termed the homalic state, that is, extended on the surface, such as are found in the protein or cellulosic monolayers. 